\title{
Comparative Evaluation of Therapy with L-Thyroxine versus No Treatment in Children with Idiopathic and Mild Subclinical Hypothyroidism
}

\author{
Malgorzata Wasniewska ${ }^{a} \quad$ Andrea Corrias $^{b}$ Tommaso Aversa $^{a}$ \\ Mariella Valenzise $^{a}$ Alessandro Mussa $^{b}$ Lucia De Martino $^{c}$ \\ Fortunato Lombardo ${ }^{a}$ Filippo De Luca ${ }^{a}$ Mariacarolina Salerno ${ }^{c}$ \\ ${ }^{a}$ Department of Pediatrics, University of Messina, Messina, ${ }^{b}$ Department of Pediatrics, University of Turin, Turin, and \\ 'Department of Pediatrics, University 'Federico II', Naples, Italy
}

\section{Key Words}

Subclinical hypothyroidism $\cdot$ L-Thyroxine therapy • Idiopathic subclinical hypothyroidism $\cdot$ Mild subclinical hypothyroidism

\begin{abstract}
Background: The question of whether children with subclinical hypothyroidism (SH) should be treated or not is controversial due to the lack of studies on outcomes of SH children treated with L-thyroxine $\left(\mathrm{L}-\mathrm{T}_{4}\right)$ versus those receiving no therapy. Objectives: (a) To evaluate thyroid tests under $\mathrm{L}_{4}$ and after therapy withdrawal in 69 SH children (group A) and (b) to compare our results with those recorded in 92 untreated children (group B). Design: Group A children were treated for 24 months and $\mathrm{TSH}$ and $\mathrm{FT}_{4}$ levels 3 months after therapy withdrawal were compared with those measured in group $\mathrm{B}$ at the end of follow-up in order to investigate treatment effects. Results: The prevalence of children who had normalized TSH at the end of follow-up was higher in group A, but the prevalence of those who had normalized or maintained unchanged TSH was similar in the two groups, as was the prevalence of children who exhibited a TSH increase $>10$ $\mathrm{mU} / \mathrm{l}$. In group A, TSH values at 27 months were associated with baseline values. Conclusions: (a) Two-year treatment in
\end{abstract}

\section{KARGER}

Fax +4161306 1234

E-Mail karger@karger.ch

www.karger.com
(C) 2012 S. Karger AG, Basel

$1663-2818 / 12 / 0776-0376 \$ 38.00 / 0$

Accessible online at:

www.karger.com/hrp
SH children is unable to modify posttherapy outcome of hyperthyrotropinemia; (b) therapy is unable to prevent the risk of further TSH increase after treatment withdrawal, and (c) posttherapy TSH outcome is conditioned by baseline TSH.

Copyright $\odot 2012$ S. Karger AG, Basel

\section{Introduction}

Subclinical hypothyroidism ( $\mathrm{SH}$ ) is a biochemical condition of moderate thyroid failure, which is defined as serum TSH level above the upper limit of reference range when serum $\mathrm{FT}_{4}$ concentration is within its reference range [1]. SH is quite common in adulthood and elderly, with the worldwide prevalence ranging from 4 to $10 \%$ in large general population screening surveys [2] and from 7 to $26 \%$ in studies of elderly [3]. In pediatric age the $\mathrm{SH}$ prevalence seems to be distinctly lower [4].

The key question is whether people with $\mathrm{SH}$ should be treated with thyroid hormones, but this is very controversial. There is no evidence to support the view that L-thyroxine $\left(\mathrm{L}-\mathrm{T}_{4}\right)$ treatment can improve hypothyroid symptoms, serum cholesterol levels or cardiac function in adults with this condition [1]. This is also confirmed by a recent meta-analysis of 2,513 articles on $\mathrm{SH}$, of which 
only 12 described randomized controlled trials comparing $\mathrm{L}^{-\mathrm{T}_{4}}$ therapy with either placebo or no treatment in adults with $\mathrm{SH}$ [5]. Meta-analysis of these trials revealed little benefit of therapy in terms of hypothyroid symptoms, quality of life, serum lipid concentrations and/or cardiac function, at least in adults [5].

In children, this is an even more controversial issue, due to the lack of controlled pediatric studies looking at outcomes of $\mathrm{SH}$ children treated with $\mathrm{L}_{4} \mathrm{~T}_{4}$, versus those receiving either placebo or no therapy [6]. Moreover, only few prospective studies have reported a natural history of $\mathrm{SH}$ in children; thus there are many concerns that, if untreated, SH may progress to overt hypothyroidism $[7,8]$.

In the present non-randomized study we have prospectively investigated, for the first time in a pediatric population, the effects of a 2-year treatment with $\mathrm{L}^{-} \mathrm{T}_{4}$ in a series of children with mild SH (TSH between 5 and 10 $\mathrm{mU} / \mathrm{l}$ ) and no underlying diseases or risk factors that might interfere with the progression of SH. The aims of our study were (a) to evaluate changes of thyroid function tests under $\mathrm{L}_{-} \mathrm{T}_{4}$ therapy and subsequent evolution after treatment withdrawal, and (b) to compare our results with those recorded in a cohort of age-matched untreated children with mild and 'idiopathic' SH who had been previously followed for 2 years, as reported elsewhere [7].

\section{Patients and Methods}

\section{Study Population and Design}

Sixty-nine selected children (17 boys) with 'idiopathic' and mild SH (group A) were enrolled according to the following inclusion criteria, aiming to exclude all etiological causes of $\mathrm{SH}$ and other risk factors that might interfere with $\mathrm{SH}$ progression: (a) no underlying diseases; (b) neither palpable goiter nor other symptoms generally associated with thyroid hypofunction; (c) normal thyroid ultrasonography (US); (d) absence of thyroid autoantibodies; (e) no anamnesis of either neck radiation therapy or false positivity at congenital hypothyroidism screening; (f) origin from iodine-sufficient areas, and (g) no concomitant therapy with either lithium salts, antiepileptic agents, glucocorticoids or iodinated drugs.

All children of this group were under 15 years of age (mean 9.4 \pm 4.0 , range 2.1-14.9) and had been referred to our pediatric endocrine units by their pediatricians because of the incidental finding of elevated TSH concentrations at their usual annual check-up which also included TSH measurement. Of these, 38 were prepubertal (55.1\%) and 31 pubertal (44.9\%), and all were in a good clinical condition.

Two measurements of serum TSH and $\mathrm{FT}_{4}$ levels with an interval of 1-3 months were required to enter the treatment protocol.

All group A children were treated with $\mathrm{L}^{-} \mathrm{T}_{4}$ for 2 years. The initial $\mathrm{L}_{-} \mathrm{T}_{4}$ dosage $(2 \mu \mathrm{g} / \mathrm{kg} /$ day $)$ was periodically adjusted on the basis of $\mathrm{FT}_{4}$ and $\mathrm{TSH}$ serum values in order to maintain these val-
Table 1. Changes in average $( \pm \mathrm{SD}) \mathrm{FT}_{4}(\mathrm{pm} / \mathrm{l}), \mathrm{TSH}(\mathrm{mU} / \mathrm{l})$, height (H SDS) and body mass index (BMI SDS) at various times in both treated and untreated groups (groups A and B, respectively) during follow-up periods (from baseline to 27 months in group A and from baseline to 24 months in group B, respectively)

\begin{tabular}{lccc}
\hline & Baseline & 24 months & 27 months \\
\hline TSH (A) & $7.7 \pm 1.7$ & $2.7 \pm 1.1^{\mathrm{a}}$ & $6.9 \pm 8.9^{\mathrm{b}, \mathrm{c}}$ \\
$\mathrm{TSH}(\mathrm{B})$ & $6.1 \pm 1.3$ & $4.7 \pm 1.3$ & \\
$\mathrm{p}$ & $<0.05$ & $<0.001$ & \\
$\mathrm{FT}_{4}$ (A) & $14.8 \pm 4.2$ & $14.9 \pm 3.0$ & $14.5 \pm 2.3$ \\
$\mathrm{FT}_{4}$ (B) & $14.3 \pm 3.4$ & $14.0 \pm 2.5$ & \\
$\mathrm{p}$ & n.s. & n.s. & \\
$\mathrm{H}(\mathrm{A})$ & $-0.3 \pm 1.4$ & $-0.2 \pm 1.2^{\mathrm{d}}$ & \\
$\mathrm{H}$ (B) & $-0.1 \pm 1.3$ & $-0.1 \pm 1.3^{\mathrm{d}}$ & \\
$\mathrm{p}$ & n.s. & n.s. & \\
$\mathrm{BMI}(\mathrm{A})$ & $-0.2 \pm 1.5$ & $1.4 \pm 5.2^{\mathrm{d}}$ & \\
$\mathrm{BMI}(\mathrm{B})$ & $-0.6 \pm 1.7$ & $1.0 \pm 3.3$ & \\
$\mathrm{p}$ & n.s. & n.s. & \\
\hline
\end{tabular}

${ }^{\mathrm{a}} \mathrm{p}<0.0005$ with respect to baseline value in the same group A.

${ }^{\mathrm{b}} \mathrm{p}<0.0005$ with respect to 24 months value in the same group A.

${ }^{c} \mathrm{p}<0.01$ with respect to 24 months value in group $B$.

$\mathrm{d}$ n.s. with respect to baseline value in the same group.

ues within the respective reference ranges during the 2-year treatment period. Height $(\mathrm{H})$, body mass index (BMI), clinical parameters, thyroid US and autoimmunity tests were evaluated both at the beginning and end of treatment period, whereas $\mathrm{FT}_{4}$ and TSH serum levels were also monitored during the therapy period and 3 months after withdrawal (27 months after follow-up onset).

All group A children and their families had been previously informed about the objectives, safety and duration of $\mathrm{L}^{-} \mathrm{T}_{4}$ treatment in order to reinforce compliance and prevent the risk of withdrawals. Patients' compliance during the 2-year treatment period was periodically evaluated in two ways: detailed questions to the children's caregivers and periodical assessments of TSH serum levels under treatment.

The control group (group B) consisted of 92 children (50 males) with mild and 'idiopathic' SH, where etiological causes of $\mathrm{SH}$ had been preliminarily excluded at the time of admission on the basis of the same inclusion criteria that were adopted for group A children. All of them were under 15 years of age (mean $8.3 \pm$ 3.0 , range $5.0-14.9)$; 67 were prepubertal $(72.8 \%)$, whilst 25 were pubertal (27.2\%). The prevalence of pubertal children in group A was significantly higher than in group B (respectively 44.9 vs. $\left.27.2 \% ; \chi^{2}=35.5, p<0.025\right)$. All these children were prospectively examined for 2 years after admission and auxological $(\mathrm{H}$ and $\mathrm{BMI}$ ), clinical and hormonal (TSH and $\mathrm{FT}_{4}$ ) parameters, thyroid US and autoimmunity tests were evaluated both at entry and at the end of a 2-year follow-up. Hormonal values recorded in this group at the end of the 24-month follow-up were compared with those recorded at baseline and with those recorded in group A 3 months after therapy withdrawal (27 months) (table 1). 
This study design was approved by the ethical committees of our hospitals and children and/or their parents gave their informed consent. Appropriate consents for this study were also obtained from the Study Group for Thyroid Diseases of the Italian Society for Pediatric Endocrinology and Diabetology (SIEDP/ISPED).

The recruitment of group A children was started 9 months after the onset of group B enrolment and was concluded 24 months after the admission of the last patient of group B.

\section{Methods}

SH was defined by elevated TSH concentrations (5-10 mU/l) in the presence of normal $\mathrm{FT}_{4}$ concentrations (10.3-24.4 pm/l). Thyroid function tests were determined in the fasting status and performed in the same laboratory for each subject. TSH and $\mathrm{FT}_{4}$ were determined by high specific fluorometric immunoassays. Intra- and interassay variations were less than $10 \%$. Thyroid autoimmunity was studied by measurement of serum levels of thyroid peroxidase antibodies (TPOAbs) and titer was considered positive for values $>20 \mathrm{U} / \mathrm{ml}$.

Thyroid US was performed in all subjects with a high-resolution $7.5 \mathrm{MHz}$ linear transducer. The analysis of thyroid volume and echogenicity in each patient was assessed by the same operator both at entry and at the end of follow-up. Clinical evaluation was aimed at ascertaining the existence of symptoms and/or signs of hypothyroidism. Auxological assessment was based on $\mathrm{H}$ measurement and BMI calculation. Standing $\mathrm{H}$ was measured with a Harpenden stadiometer (Holtain Ltd, Crymych, Dyfed, UK). BMI was calculated as weight divided by squared $\mathrm{H}\left(\mathrm{kg} / \mathrm{m}^{2}\right)$. To allow the comparison between different ages and genders, $\mathrm{H}$ and BMI were expressed as SD scores according to the standards assessed by Cacciari et al. [9].

\section{Statistical Analysis}

Results are expressed as mean values; variability is indicated by SD and/or value range. For comparisons of two groups we used the Student $t$ test for both paired and unpaired data (normally distributed data) and either the Mann-Whitney U test or the Wilcoxon test (non-parametric data), as appropriate. Frequency rates were compared by $\chi^{2}$ test. Correlations between quantitative variables were assessed using Pearson's correlation analysis. The level of significance was set at 0.05 .

\section{Results}

\section{Changes in $\mathrm{FT}_{4}$ and TSH Serum Levels and Other}

\section{Thyroid Tests under $L-T_{4}$ Treatment}

In all group $\mathrm{A}$ children, $\mathrm{FT}_{4}$ levels remained within a normal range (10.3-24.4 $\mathrm{pm} / \mathrm{l})$ throughout the overall follow-up, from entry to 27 months (i.e. during $\mathrm{L}^{-} \mathrm{T}_{4}$ therapy and 3 months after therapy withdrawal). Mean $\mathrm{FT}_{4}$ concentrations did not significantly change during follow-up, as compared with both pre- and posttreatment $\mathrm{FT}_{4}$ values and with mean $\mathrm{FT}_{4}$ values measured in group $B$ at 24 months (table 1).

TSH levels significantly decreased under therapy in group A and increased again after therapy withdrawal
Table 2. Percentages of children in both treated and untreated groups (groups A and B, respectively) who either had normalized TSH values $(<5 \mathrm{mU} / \mathrm{l})$ or maintained the initial TSH values $(5-10$ $\mathrm{mU} / \mathrm{l})$, or exhibited an increase of TSH $>10 \mathrm{mU} / \mathrm{l}$, after a 24 -month follow-up (in both groups) and 3 months after $\mathrm{L}-\mathrm{T}_{4}$ therapy withdrawal (only in group A)

\begin{tabular}{rlll}
\hline & Baseline & 24 months & 27 months \\
\hline TSH $<5$ mU/1 & & & \\
Group A, \% & 0 & 100 & $60.9^{\mathrm{a}}$ \\
Group B, \% & 0 & 41.3 & \\
TSH 5-10 mU/1 & & & \\
Group A, \% & 100 & 0 & $21.7^{\mathrm{b}}$ \\
Group B, \% & 100 & 46.7 & \\
TSH >10 mU/1 & & & $17.4^{\mathrm{c}}$ \\
Group A, \% & 0 & 0 & \\
Group B, \% & 0 & 12.0 &
\end{tabular}

${ }^{\mathrm{a}} \chi^{2}=6.0, \mathrm{p}<0.025$ with respect to 24 months in group $\mathrm{B}$.

${ }^{\mathrm{b}} \chi^{2}=10.7, \mathrm{p}<0.005$ with respect to 24 months in group $\mathrm{B}$.

${ }^{c} \chi^{2}=0.9, p=$ n.s. with respect to 24 months in group $B$.

(table 1), with a significant increase of $4.2 \pm 7.1 \mathrm{mU} / \mathrm{l}$, which was unrelated to either sex or age or pubertal status or concomitant $\mathrm{FT}_{4}$ changes. Mean TSH values at 27 months were still significantly higher compared to those recorded in group B at the end of the 24-month follow-up (table 1).

At the end of the 2-year treatment period, findings of Hashimoto's thyroiditis (HT) were detected at thyroid US in $5 / 69$ patients of group A (vs. $2 / 92$ in group $B ; \chi^{2}=2.4$, $\mathrm{p}=$ n.s., respectively). In group A, TPOAbs remained undetected during the entire treatment period in all but 5 children, i.e. the 5 children showing US findings of HT.

\section{Posttherapy TSH Outcome}

Overall, 42 of the 69 group A children (60.9\%) maintained normal TSH concentrations 3 months after therapy withdrawal (table 2). In $6 / 42(14.3 \%)$ the posttherapy TSH values were $<2 \mathrm{mU} / 1$, in $7 / 42$ (16.7\%) TSH levels were between 2 and $3 \mathrm{mU} / \mathrm{l}$, whereas in the remaining children (29/42, i.e. 69.0\%) achieved TSH levels between $>3$ and 4.9 $\mathrm{mU} / \mathrm{l}$.

Among the remaining 27 group A children who did not have normalized TSH concentrations at the end of observation period, the majority (55.6\%) maintained TSH within baseline limits (5-10 mU/l). Twelve out of 27 (44.4\%) exhibited a further increase in TSH levels $>10$ $\mathrm{mU} / 1$ despite persistently normal $\mathrm{FT}_{4}$ levels (table 2). Among these 12 children, 8 increased TSH to 10.1-15.0, 
Table 3. Percentage distribution of the $69 \mathrm{~L}-\mathrm{T}_{4}$-treated children into two subgroups with different posttherapy TSH outcome and average $( \pm S D)$ baseline TSH values $(\mathrm{mU} / \mathrm{l})$ and cumulative $\mathrm{L}_{-} \mathrm{T}_{4}$ dosage ( $\mu \mathrm{g} /$ day) (during the entire therapy period) in these subgroups

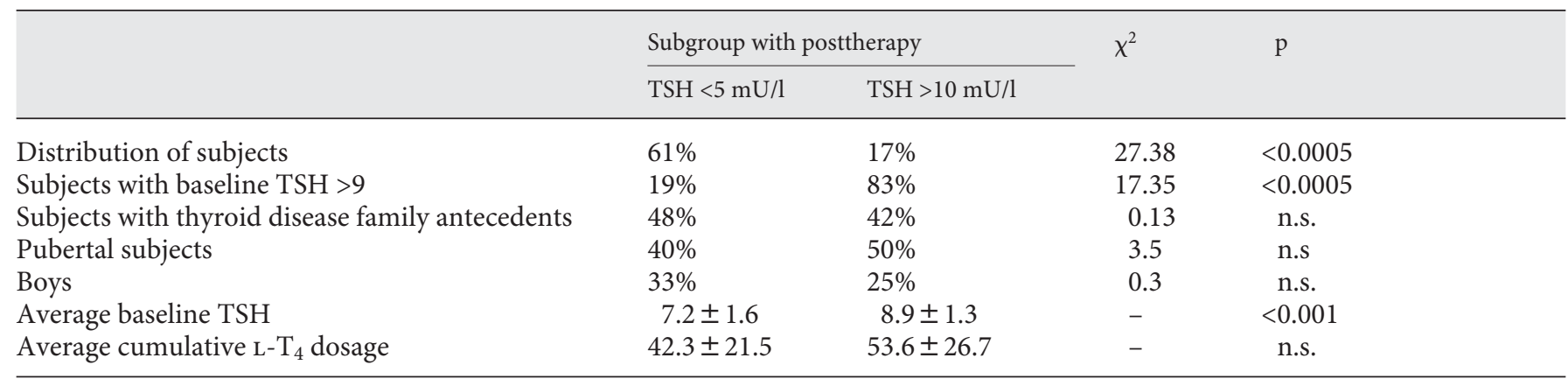

only 1 to $15.1-20.0$, and the remaining $3>20 \mathrm{mU} / \mathrm{ml}$. In only 1 of them was the TSH increase (to $13.9 \mathrm{mU} / \mathrm{l}$ ) also associated with both TPOAb detection and thyroid US features of $\mathrm{HT}$ at the end of follow-up.

Percentages of children with either decreasing, increasing or stable TSH values in both groups are summarized in table 2 . The prevalence of normalizers was significantly higher in group A than in group $B$, whereas the overall prevalence of children who either had normalized or maintained unchanged TSH was very similar in the two groups ( 82.6 vs. $88 \% ; \chi^{2}=0.95$, $p=$ n.s., respectively), as well as that of children who exhibited a further increase in TSH levels $>10 \mathrm{mU} / \mathrm{l}$ (table 2).

\section{Factors Influencing Posttherapy TSH Outcome in Treated Children}

In the 42 group A children who had normalized TSH values at the end of the 27 -month observation period, baseline TSH values were significantly lower compared to those recorded in the 12 children who had increased TSH values to $>10 \mathrm{mU} / \mathrm{l}$ during the same period (table 3 ). In $10 / 12$ children with posttherapy TSH values $>10 \mathrm{mU} / \mathrm{l}$, baseline TSH was $>9 \mathrm{mU} / \mathrm{l}$ (from 9.3 to 10 ) and the prevalence of subjects with baseline TSH $>9 \mathrm{mU} / \mathrm{l}$ was significantly higher in this cohort than among the 42 normalizers (table 3). Overall, in group A, TSH values at 27 months were positively associated with baseline $(r=0.27$, $\mathrm{p}<0.05)$, but not with either baseline $\mathrm{FT}_{4}$ values or 24-month TSH values.

In group A the prevalence of children who either had normalized or increased TSH values to $>10 \mathrm{mU} / \mathrm{l}$ was not significantly conditioned by either pubertal status or sex (table 3). Neither the prevalence of family history of thyroid diseases nor the cumulative $\mathrm{L}-\mathrm{T}_{4}$ dosage during the 24-month treatment period were significantly different among the children who had normalized and those who had increased TSH values to $>10 \mathrm{mU} / \mathrm{l}$ (table 3 ).

\section{Clinical and Auxological Data}

None of the group A children showed any clinical signs or symptoms of hypothyroidism at entry or after treatment withdrawal. Both at entry and 24 months later, no significant differences between the two groups were found in terms of either H or BMI SDS (table 1). In spite of the apparent increase of BMI SDS observed in group A during the 2-year follow-up (table 1), the percentage of overweight children remained stable in this group during the same period (from 18.8 to $17.4 \%$ ). BMI and H SDS did not significantly change during follow-up in either group (table 3). In group A there was no difference in $\mathrm{H}$ and BMI evolution during the overall treatment period in the 42 children who had normalized TSH after therapy withdrawal, compared to those who did not.

\section{Compliance with $L-T_{4}$ Therapy and Withdrawals}

Compliance with therapy of group A children was very good, as confirmed by both the significant decrease of average TSH levels recorded under treatment (table 1) and the normalization of hyperthyrotropinemia observed in all cases (table 2). No withdrawals were recorded in both groups during the entire study period and all 161 children who were included were followed up until the conclusion of the predetermined study period.

\section{Discussion}

$\mathrm{SH}$ is a relatively common finding in children and the few available follow-up studies on pediatric populations indicate that the majority of children with slightly elevat- 
ed TSH levels and no underlying disease are likely to normalize TSH without treatment or have persistently mild TSH elevation $[7,10]$. The evidence for benefit of $\mathrm{L}^{-\mathrm{T}_{4}}$ supplementation for children with mild TSH elevation is very poor, although this does not necessarily imply lack of benefit [11]. If there is an underlying HT, treatment is more likely to be advisable, since progression from $\mathrm{SH}$ to overt hypothyroidism is more likely [12]. In the present study, however, an underlying HT had been preliminarily excluded according to our recruitment criteria.

This is the first pediatric study reporting the results of a 2-year L- $\mathrm{T}_{4}$ treatment in $\mathrm{SH}$ children. Our endpoint was to evaluate whether such treatment could modify the natural course of 'idiopathic' and mild SH, in terms of posttherapy normalization of hyperthyrotropinemia.

According to the present data, the results of this treatment on thyroid function might be considered as disappointing, although the prevalence of normalizers was significantly higher in group A. Nevertheless, it must be considered that the overall prevalence of individuals who either had normalized or maintained initial TSH values after therapy withdrawal was very similar to the prevalence observed in untreated children at the end of followup; also, the prevalence of children who had increased TSH levels $>10 \mathrm{mU} / \mathrm{l}$ at the last examination was not significantly different in the two groups. Moreover, average TSH values found in the treated group after therapy withdrawal were significantly higher compared to those detected in the untreated group at the end of follow-up.

Posttherapy TSH outcome in the treated group was significantly affected by pretreatment TSH values: the higher baseline TSH was the higher TSH serum levels were 3 months after treatment withdrawal. These findings are in accordance with those reported by other authors in both adults [13] and children [10] with SH and confirm that baseline TSH concentration is the most powerful predictor of SH evolution over time. The stable and even worsening TSH elevation recorded in the present study in some children of both groups might be the expression of mild mutations of TSH receptor gene, which are known to be a possible cause of TSH resistance and apparently idiopathic SH [14-17]. Children with TSH receptor gene mutations and consequent TSH resistance are likely to need supranormal amounts of TSH to adequately stimulate the thyroid, and persistence over time of an SH condition is not surprising in these subjects. Therefore, in the cases with either persistent or even worsening TSH elevation after prolonged follow-up, $\mathrm{L}_{-} \mathrm{T}_{4}$ treatment is probably very advisable.

Finally, according to the present study, both $\mathrm{L}-\mathrm{T}_{4}$ therapy and no treatment in children with mild and idiopathic SH do not have any relevant repercussions on the subsequent evolution of auxological parameters. However, it should be underlined that all group A children had normal growth and, therefore, it is not surprising that $\mathrm{L}-\mathrm{T}_{4}$ therapy was ineffective in this auxological scenario. The data on BMI are potentially interesting, with a greater increase for group A compared to group B. Although this difference did not achieve statistical relevance and the percentage of overweight children in group A remained stable, this is an area that might warrant further investigation.

In conclusion: (a) 2-year treatment with $\mathrm{L}^{-\mathrm{T}_{4}}$ in children with 'idiopathic' and mild SH is not able to distinctly modify the natural course of $\mathrm{SH}$, at least in terms of posttherapy outcome of hyperthyrotropinemia; (b) therapy is not able to prevent the risk of further increase of TSH after treatment withdrawal, and (c) posttherapy outcome of TSH serum levels is significantly conditioned by baseline TSH.

\section{References}

1 Surks MI, Ortiz E, Daniels GH, Sawin CT, Col NF, Cobin RH, Franklyn JA, Hershman JM, Burman KD, Denke MA, Gorman C, Cooper RS, Weissman NJ: Subclinical thyroid disease: scientific review and guidelines for diagnosis and management. JAMA 2004; 291:228-238.

$\checkmark 2$ Chu JW, Crapo LM: The treatment of subclinical hypothyroidism is seldom necessary. J Clin Endocrinol Metab 2001;86:4591-4599.

3 McDermott MT, Ridgway EC: Subclinical hypothyroidism is mild thyroid failure and should be treated. J Clin Endocrinol Metab 2001;86:4585-4590.
4 Wu T, Flowers JW, Tudiver F, Wilson JL, Punyasavatsut N: Subclinical thyroid disorders and cognitive performance among adolescents in the United States. BMC Pediatr 2006;6:12.

5 Villar HCCE, Saconato H, Valente O, Atallah AN: Thyroid hormone replacement for subclinical hypothyroidism. Cochrane Database Syst Rev 2007;18:CD003419.

6 Kaplowitz PB: Subclinical hypothyroidism in children: normal variation or sign of a failing thyroid gland. Int J Pediatr Endocrinol 2010;2010:281453.

\footnotetext{
7 Wasniewska M, Salerno M, Cassio A, Corrias A, Aversa T, Zirilli G, Capalbo D, Bal M, Mussa A, De Luca F: Prospective evaluation of the natural course of idiopathic subclinical hypothyroidism in childhood and adolescence. Eur J Endocrinol 2009;160:417421.

-8 Cerbone M, Bravaccio C, Capalbo D, Polizzi $\mathrm{M}$, Wasniewska M, Cioffi D, Improda N, Valenzise M, Bruzzese D, De Luca F, Salerno M: Linear growth and intellectual outcome in children with long-term idiopathic subclinical hypothyroidism. Eur J Endocrinol 2011; 164:591-597.
} 
-9 Cacciari E, Milani S, Balsamo A, and Directive Councils of SIEDP/ISPED for 1996-1997 and 2002-2003: Italian cross-sectional growth charts for height, weight and BMI (2-20 years). J Endocrinol Invest 2006;29:581-593.

10 Lazar L, Frunklin RB, Battat E, Lebenthal Y, Philip M, Meyerovitch J: Natural history of thyroid function tests over 5 years in a large pediatric cohort. J Clin Endocrinol Metab 2009;94:1678-1682.

- 11 O'Grady MJ, Cody D: Subclinical hypothyroidism in childhood. Arch Dis Child 2011; 96:280-284.

-12 Radetti G, Maselli M, Buzi F, Corrias A, Mussa A, Cambiaso P, Salerno M, Cappa M, Baiocchi M, Gastaldi R, Minerba L, Loche S: The natural history of the normal/mild elevated TSH serum levels in children and adolescents with Hashimoto's thyroiditis and isolated hyperthyrotropinemia: a 3-year follow-up. Clin Endocrinol 2012;76:394-398.
13 Diez JJ, Iglesias P: Spontaneous subclinical hypothyroidism in patients older than 55 years: an analysis of natural course and risk factors for the development of overt thyroid failure. J Clin Endocrinol Metab 2004;89: 4890-4897.

14 Tonacchera M, Perri A, De Marco G, Agretti P, Banco ME, Di Cosmo C, Grasso L, Vitti P, Chiovato L, Pinchera A: Low prevalence of thyrotropin receptor mutations in a large series of subjects with sporadic and familial non-autoimmune subclinical hypothyroidism. J Clin Endocrinol Metab 2004;89:57875793.

5 Nicoletti A, Bal M, De Marco G, Baldazzi L, Agretti P, Menabò S, Ballarini E, Cicognani A, Tonacchera M, Cassio A: Thyrotropinstimulating hormone receptor gene analysis in pediatric patients with non-autoimmune subclinical hypothyroidism. J Clin Endocrinol Metab 2009;94:4187-4194.
16 Rapa A, Monzani A, Moia S, Vivenza D, Bellone S, Petri A, Teofoli F, Cassioi A, Cesaretti G, Corrias A, de Sanctis V, Di Maio S, Volta C, Wasniewska M, Tatò L, Bona G: Subclinical hypothyroidism in children and adolescents: a wide range of clinical, biochemical, and genetic factors involved. J Clin Endocrinol Metab 2009;94:2414-2420.

17 Celebiro D, Gelmini G, Cordella D, Bonomi M, Winkler F, Biebermann H, de Marco A, Marelli F, Libri DV, Antonica F, Vigone MC, Cappa M, Mian C, Santorio A, Beck-Peccoz P, Radetti G, Weber G, Persani L: Frequent $\mathrm{TSH}$ receptor genetic alterations with variable signaling impairment in a large series of children with non-autoimmune isolated hyperthyrotropinemia. J Clin Endocrinol Metab 2012;97:E156-E160. 